\begin{abstract}
Iranica
Abstracta Iranica Revue bibliographique pour le domaine irano-aryen

Volume 37-38-39 | 2018

Comptes rendus des publications de 2014-2016
\end{abstract}

\title{
Geoffrey Herman. Persian Martyr Acts under King Yazdgird I
}

\section{Christelle Jullien}

\section{(2) OpenEdition \\ 12 Journals}

\section{Édition électronique}

URL : http://journals.openedition.org/abstractairanica/44301

DOI : 10.4000/abstractairanica.44301

ISBN : 1961-960X

ISSN : 1961-960X

Éditeur :

CNRS (UMR 7528 Mondes iraniens et indiens), Éditions de l'IFRI

Référence électronique

Christelle Jullien, « Geoffrey Herman. Persian Martyr Acts under King Yazdgird I », Abstracta Iranica [En ligne], Volume 37-38-39 | 2018, document 14, mis en ligne le 30 décembre 2018, consulté le 10 décembre 2020. URL : http://journals.openedition.org/abstractairanica/44301 ; DOI : https://doi.org/ 10.4000/abstractairanica.44301

Ce document a été généré automatiquement le 10 décembre 2020.

Tous droits réservés 


\title{
Geoffrey Herman. Persian Martyr Acts under King Yazdgird I
}

\author{
Christelle Jullien
}

\section{RÉFÉRENCE}

Geoffrey Herman. Persian Martyr Acts under King Yazdgird I. Piscataway: Gorgias Press, 2016, 91 p., (Persian Martyr Acts in Syriac: Text and Translation 5), ISBN

978-1-4632-0623-9.

Cinq textes martyrologiques syriaques de l'époque du roi sassanide Yazdgird $\mathrm{I}^{\mathrm{er}}$ (399-420) sont présentés avec traduction anglaise et texte syriaque en vis-à-vis (curieusement en caractères serțo pour des textes de l'Église de Perse), dont les résumés substantiels sont donnés dans la brève introduction, ainsi que leur intérêt historique et littéraire. Il s'agit d'abord de l'histoire de Narsaï (Narse[h]), présenté à tort par l'A. comme un «moine » (p. XVI, p. 2) alors qu'il est un laïc consacré, membre de l'Alliance (bar q'yama). Certains partis-pris de traduction ne sont pas corrects («mage » pour «zoroastrien» par exemple p. 2 et n. 4, les mages correspondant à une fonction administrative religieuse bien précise dans la hiérarchie ecclésiale mazdéenne). Le second récit, l'histoire de Ṭātāq, raconte la conversion et le martyre d'un grand intendant de la cour (l'écrivain syriaque utilise le mot dwmstyq', « domestique »). On notera la lettre tet (T) à l'initiale du nom (et non pas taw, p. XVI, p. 28-34). Le troisième texte martyrologique concerne dix laïcs originaires de la région du Bēth-Garmaï : Ohrmazd, Aiti, Māri, Ani, Ati, Ja' qūb, Ḥurā, Pāpā, Nemrod, Ādur-Farrox. On pourrait aussi traduire "la citadelle de Lawarnē» (p. 44) en une expression toponymique : Hesna d-Lawarnē, comme il existe Hesna 'Ebrāyā en rive droite du Tigre, sur l'emplacement de l'ancienne Mossoul. La quatrième Passion, fragmentaire, est celle du martyr Šābuhr : l'A. redonne ici la traduction qu'il avait publiée dans le Journal of Semitic Studies 58, 2013, p. 121-130. Enfin, l'histoire de Mār 'Abdā et de ses compagnons 
(les prêtres Hašu et Isaac, le scribe Éphrem, le sous-diacre Pāpā, les laïcs Dādūq et Dūrtān, et Pāpā frère du protagoniste) termine l'ensemble.

On regrettera que le contexte politique, social, culturel, économique, ecclésial, n'ait pas été plus amplement abordé : il aurait mérité un commentaire détaillé. Les limites imparties par la collection expliqueraient peut-être la concision de l'introduction. Même si les notes de bas de page donnent parfois d'intéressante indications, notamment des parallèles avec la littérature talmudique (cf. p. 30 n. 72, p. 36 n. 80, p. 38 n. 83) ou pehlevie (introduction, p. XXIII), il eut été bien utile d'éclaircir l'ancrage historique de ces personnages, ainsi que les constructions narratives et les élaborations scripturaires. Le débat sur la politique religieuse de Yazdgird $\mathrm{I}^{\mathrm{er}}$ et ses revirements est limité à une présentation de références bibliographiques dans une note de bas de page (n. 1 p. XV-XVI). Le $\mathrm{V}^{\mathrm{e}}$ siècle est pourtant une période-clef où les minorités religieuses de l'empire (juifs, communautés chrétiennes dans leur diversité, manichéens, etc.) ont créé les conditions d'un nouveau rapport au pouvoir. C'est à ce moment que se met en place l'organisation juridictionnelle de l'Église d'Orient, que s'élaborent ses titres d'autorité référents, que sa visibilité se renforce dans un contexte pourtant difficile. L'A. indique en introduction les traductions existantes, partielles ou complètes, et donne un très bref état de la tradition manuscrite ( $\mathrm{p}$. XXV). La présentation par paragraphes est très commode; conséquemment, la mise en page laisse parfois, curieusement, de grands espaces blancs (p. 12-15, p. 22-27, p. 32-35, p. 42-45). Un choix bibliographique ouvre l'étude (p. IX-XII). Une table des matières plus détaillée, avec renvoi à chacune des Passions, eut été appréciée. L'un des mérites de ce volume est bien de mettre à disposition ce corpus de textes pour un public élargi.

\section{AUTEURS}

\section{CHRISTELLE JULLIEN}

CNRS, Mondes iranien et indien, Paris 